\title{
PRODUÇÃO E COMPOSIÇÃO DE MILHETO UTILIZANDO DIFERENTES FONTES DE NITROGÊNIO.
}

\author{
Alan Soares Machado ${ }^{1}$; Douglas Dijkstra ${ }^{1}$; Lidiane Oliveira Silva ${ }^{1}$; Hanna Deise Santos Barbosa ${ }^{1}$; Taiz \\ Borges Ribeiro ${ }^{1}$; Wilian Henrique Diniz Buso ${ }^{1}$; Halef Pereira de Oliveira ${ }^{1}$; Dábio Silva dos Reis ${ }^{1}$ \\ ${ }^{1}$ Instituto Federal Goiano - Campus Ceres. e-mail: halefpgtu15@hotmail.com
}

\begin{abstract}
RESUMO
Avaliou-se neste estudo os efeitos de doses crescentes e diferentes fontes de $\mathrm{N}$ na produção, composição bromatológica e o $\mathrm{N}$ contido na parte aérea das plantas de milheto forrageiro em condições de cerrado. Foram utilizadas duas fontes de N (ureia e Novatec), quatro dosagens $(0,40$, 80 e $160 \mathrm{~kg} \mathrm{ha}^{-1}$ ) e três cortes, com quatro repetições totalizando 32 unidades experimentais. Os cortes de avaliação foram efetuados quando, no mínimo, $50 \%$ das plantas atingiram $0,80 \mathrm{~m}$ de altura. As variáveis analisadas foram PMV, PMS, MS, PB, FDN, FDA e NC de todos os cortes. Não ocorreu interação significativa entre as varáveis analisadas para fontes e doses de $\mathrm{N}$, doses de $\mathrm{N}$ e cortes, cortes e fontes de $\mathrm{N}$ e também a interação tripla fontes, cortes e dose de $\mathrm{N}$. A PMS foi superior o segundo e terceiro (1.691 e $1.862 \mathrm{~kg} \mathrm{ha}^{-1}$, respectivamente) corte que diferiram do primeiro (1362 $\left.\mathrm{kg} \mathrm{ha}^{-1}\right)$. A MS foi estatisticamente diferente no terceiro $(15,44 \%)$ corte e semelhantes no primeiro e segundo cortes $(12,30$ e $13,08 \%$, respectivamente). O teor de PB diferiu significativamente $(P<0,05)$ em todos os cortes onde o primeiro corte diferiu do segundo corte e o terceiro corte diferiu dos demais. Os teores de FDN e FDA diferiram entre os cortes, aumentando conforme avançou os cortes. As duas fontes de $\mathrm{N}$ são adequadas para $\mathrm{O}$ fornecimento de $\mathrm{N}$ para a cultura do milheto.
\end{abstract}

Palavras-chave: forragem; nutrição; Pennisetum glaucum.

PRODUCTION AND COMPOSITION OF MILLET USING DIFFERENT NITROGEN SOURCES.

\begin{abstract}
Were noted in this study the effects of increasing doses and different nitrogen sources in the production, chemical composition and the $\mathrm{N}$ contained in the shoots of millet forage conditions in the Bioma Cerrado. Two N sources (urea and Novatec), four doses $\left(0,40,80\right.$ and $160 \mathrm{~kg} \mathrm{ha}^{-1}$ ) and three cuts with four replicates totaling 32 experimental units were used. The cuts were made assessment when at least $50 \%$ of the plants reached $0.80 \mathrm{~m}$ in height. The variables analyzed were GMP, DMP, DM, CP, NDF, ADF and CN of all cuts. There was no significant interaction between the variables analyzed for sources and rates of $\mathrm{N}, \mathrm{N}$ and cuts, cuts and sources of $\mathrm{N}$ and also the triple interaction sources, cuts and N. The dose of GMP was higher than the second and third (1691 and $1862 \mathrm{~kg} \mathrm{ha}^{-1}$, respectively) that differed from the first cut $\left(1362 \mathrm{~kg} \mathrm{ha}^{-1}\right)$. The MS was statistically different from the third (15.44\%) and similar cutting the first and second sections (12.30 and $13.08 \%$, respectively). The CP content significantly in all courts where the first cut differed from the second cut and third cut differed from the others. The NDF and ADF differed between cuts, rising as the cuts progressed. The two $\mathrm{N}$ sources are suitable for supplying $\mathrm{N}$ to growing millet.
\end{abstract}

Keywords: drilling; nutrition; Pennisetum glaucum. 


\section{INTRODUÇÃO}

Com a expansão do rebanho bovino brasileiro, tanto a bovinocultura de corte como a bovinocultura de leite, são dependentes, de forma crescente, da maximização da produção de forrageiras, já que, os volumosos são à base da alimentação desses animais, o que permite produzir proteína animal de qualidade a custos menores.

O milheto (Pennisetum americanum CL, Leeke [P. glaucum (L) R. Br]) é uma gramínea forrageira anual de verão, considerada uma pastagem de dias longos. É uma espécie cespitosa de porte ereto, apresenta perfilhamento abundante com estatura do colmo superior a 3,0 m podendo atingir $1,5 \mathrm{~m}$ aos 50 dias após a emergência (FRIBOURG, 1985).

O milheto tem sido amplamente usado em diversas modalidades de cultivo, como formador de palha para plantio direto (Spehar; Trecenti, 2011), forragem para pastejo direto (COSTA et al., 2011). A sua utilização para pastejo pode ser uma alternativa para aumentar a disponibilidade de forragem nos meses de transição chuva/seca e seca/chuva, porque prolonga a estação de pastejo e reduz a demanda por alimentos armazenados, além de promover um descanso para a recuperação completa do pasto no início da estação chuvosa. Em sistemas de integração lavoura-pecuária, praticado em regiões tropicais, pode ser cultivado no outono/inverno para pastejo, durante o período seco, suspendendo-se o pastejo, no início do período chuvoso, para rebrota e acúmulo de massa para plantio direto (QUEIROZ et al., 2012).

De acordo com Santos et al. (2005) o milheto pode ser uma alternativa para pastejo no verão, quando comparado com pastagens nativas, tem capacidade de produzir cinco vezes mais forragem que os campos nativos, assim permite incrementos a taxa de lotação e o ganho de peso vivo por área. Quando utilizado para pastejo o valor bromatológico varia no decorrer do seu ciclo. Os mesmos autores encontraram valores de massa seca (MS), proteína bruta (PB) e fibra em detergente neutro (FDN) de 15,2; 16,4 e 61,9\%, respectivamente, quando avaliaram o milheto aos 35 dias de crescimento vegetativo em condições de pastejo, antes da entrada dos animais no piquete.

De acordo com Fagundes et al. (2006) o fornecimento de $\mathrm{N}$ em quantidades adequadas ao longo do período de desenvolvimento das plantas forrageiras, exerce papel fundamental no crescimento das pastagens, devido o $\mathrm{N}$ proveniente da mineralização da matéria orgânica não suprir a necessidade de forrageiras de elevada produtividade.

O nitrogênio é o nutriente mais importante para aumentar a produtividade das gramíneas forrageiras, sendo o principal constituinte das proteínas que participam ativamente na síntese dos compostos orgânicos que formam a estrutura vegetal. É, portanto, responsável por características imprescindíveis nas plantas, tais como tamanho da folha e do colmo, aparecimento dos perfilhos, dentre outras (SIMILI et al., 2010).

Camargo et al. (2009) relatam teores de médios de 20\% PB em pastagem de milheto com adubação de $100 \mathrm{~kg} \mathrm{ha}^{-1}$, aos 21 dias após a germinação.

Diante do exposto objetivou avaliar diferentes doses e fontes de $\mathrm{N}$ na produção, composição bromatológica e $\mathrm{N}$ contido na parte aérea das plantas de milheto forrageiro em condições de cerrado.

\section{MATERIAL E MÉTODOS}

O experimento foi conduzido na Fazenda Experimental do Instituto Federal Goiano-Campus Ceres, localizado na Rodovia GO 154, km 03, Zona Rural, no município de Ceres-GO no período de janeiro a março de 2013. Na Figura 1 está representada o regime hídrico durante o período experimental. 
Figura 1. Precipitação $(\mathrm{mm})$ e temperatura $\left({ }^{\circ} \mathrm{C}\right)$ durante o período experimental (janeiro a maio de 2013). Fonte: Estação meteorológica do IF Goiano - Campus Ceres.

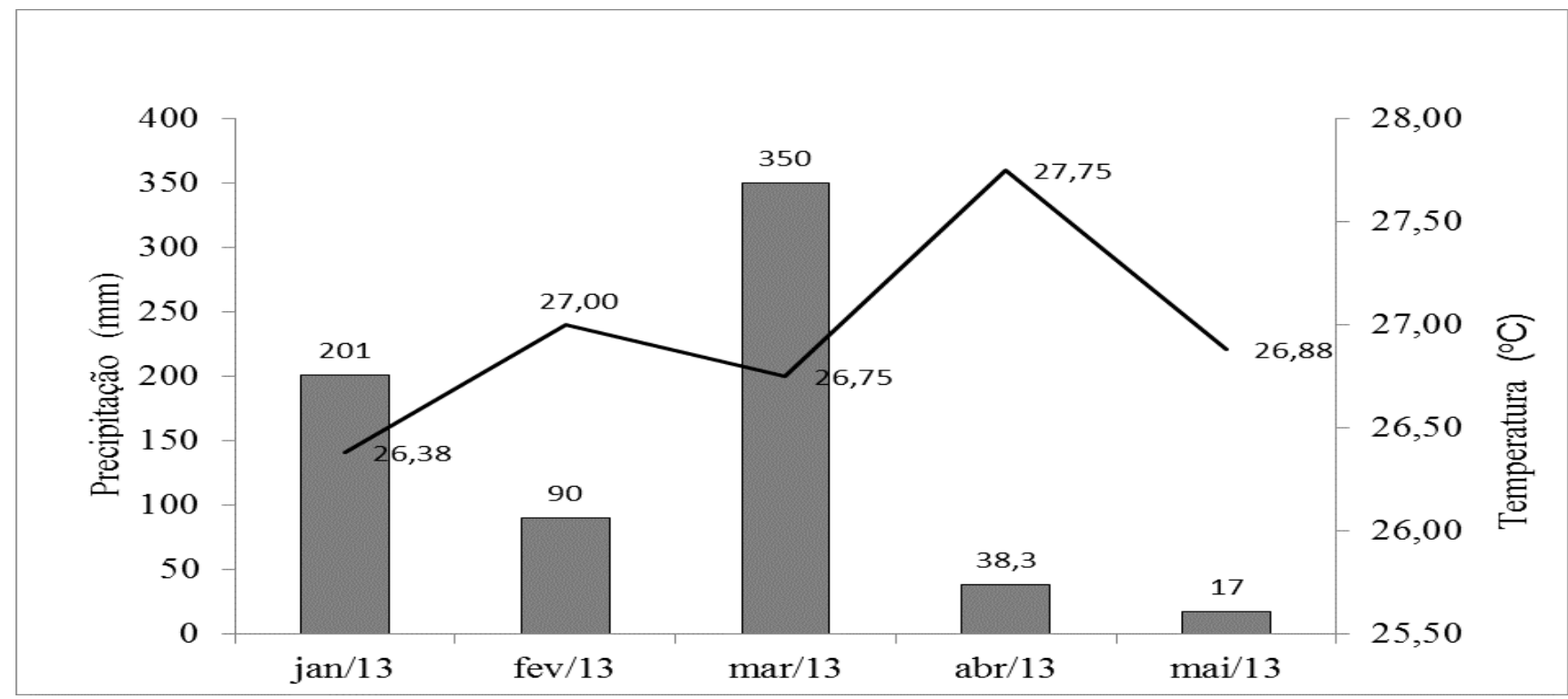

O solo da área experimental é classificado com Latossolo Vermelho distrófico, e para fins de sua caracterização química foram coletadas amostras na profundidade de 0 a $20 \mathrm{~cm}$. Os resultados da análise química da área experimental antes da instalação do experimento foram: $\mathrm{Ca}=2,03 ; \mathrm{Mg}=1,47 ; \mathrm{CTC}=8,35 ; \mathrm{Al}=0,01$ e $\mathrm{H}=4,59\left(\mathrm{cmol}_{\mathrm{c}} \mathrm{dm}^{-3}\right), \mathrm{P}(\mathrm{Mel})=10,85$ e $\mathrm{K}=65\left(\mathrm{mg} \mathrm{dm}^{-3}\right)$ e $\mathrm{V}=55,17 ; \mathrm{MO}=2,25 ;$ Areia $=39$ e Argila=40 (\%).

Foi utilizada a cultivar de milheto forrageiro Nutrifeed, em delineamento de blocos casualizados em esquema fatorial $2 \times 4 \times 3$, duas fontes de $N$ (ureia e Novatec), quatro doses $(0,40$, 80 e $160 \mathrm{~kg} \mathrm{ha}^{-1}$ ) e três cortes, com quatro repetições, totalizando 32 unidades experimentais. A fonte Ureia possui $45 \%$ de $\mathrm{N}$ e o Novatec é um sulfonitrato que possui $24 \%$ de $\mathrm{N}$ e $5 \%$ de $\mathrm{S}$ tratado com inibidor da nitrificação chamado dimetilpirazolfosfato (DMPP). O DMPP deixa o N estabilizado na forma de $\mathrm{NH}_{4}{ }^{+}$por um período de oito semanas no solo e assim reduz a lixiviação.

A semeadura foi realizada no dia 03/02/2013, utilizando a adubação de semeadura com $\mathrm{P}_{2} \mathrm{O}_{5}$ de $90 \mathrm{~kg} \mathrm{ha}^{-1}$ na forma de Super Fosfato Simples. Quinze dias após a semeadura foi realizado a adubação em cobertura com $40 \mathrm{~kg} \mathrm{ha}^{-1}$ de $\mathrm{K}_{2} \mathrm{O}(\mathrm{KCl})$ e os tratamentos com adubação nitrogenada foi realizado em uma única aplicação. Os cortes foram realizados nos dias 09/03/2013, 29/03/2013 e 19/04/2013, a uma altura de 0,25 m em relação ao solo.

Cada unidade experimental foi constituída por quatro fileiras de cinco metros lineares e espaçamento de $0,30 \mathrm{~m}$, entre linha, totalizando $6 \mathrm{~m}^{2}$. Considerou-se como parcela útil as duas fileiras centrais, eliminando-se $0,30 \mathrm{~m}$ de cada extremidade. A parcela útil foi de $3,0 \mathrm{~m}^{2}$. Os cortes de avaliação foram efetuados quando, no mínimo, $50 \%$ das plantas atingiram $0,80 \mathrm{~m}$ de altura conforme Leão et al. (2012). Após cada corte de avaliação, foi realizada a pesagem do material

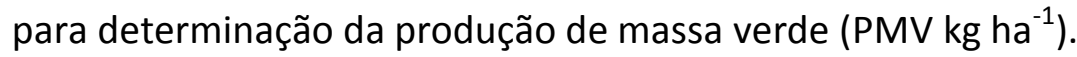

Foram retiradas amostras de aproximadamente $500 \mathrm{~g}$ para as análises laboratoriais. As amostras foram secas a $60^{\circ} \mathrm{C}$ até peso constante, em estufa de circulação forçada e moídas em moinho tipo Willey com peneira de um $\mathrm{mm}$, armazenadas em frascos de acrílico com tampas de plástico e devidamente identificadas.

As variáveis analisadas foram: produção de massa verde (PMV), matéria seca (MS), proteína bruta (PB), fibra em detergente neutro (FDN) e ácido (FDA), Nitrogênio contido na planta (NC) de todos os cortes. 
A composição bromatológica e $\mathrm{N}$ foram determinadas conforme a metodologia descrita por (SILVA; QUEIROZ, 2002).

Os dados de produção de MV, MS, composição bromatológica, NC, foram submetidos à análise variância, incluindo todos os cortes e as médias comparadas pelo teste de SkottKnott ao nível de $5 \%$ de significância. As variáveis também foram avaliadas ajustando-se equações de regressão em função da dose de $\mathrm{N}$ aplicadas em cobertura. As análises foram realizadas com auxílio do software R (R Development Core Team, 2013).

\section{RESULTADOS E DISCUSSÃO}

A análise de variância não identificou interações significativas $(p>0,05)$ entre fontes e doses de $\mathrm{N}$, doses de $\mathrm{N}$ e cortes, cortes e fontes de $\mathrm{N}$ e também a interação tripla fontes, cortes e dose de $\mathrm{N}$ para as variáveis PMV, PMS, MS, PB, FDN, FDA e NC.

Não ocorreu diferença significativa $(P>0,05)$ para as fontes de $N$ para as variáveis $P M V$, PMS e teor de MS, conforme apresentado na Tabela 1. Para os diferentes cortes não ocorreu diferença significativa $(P>0,05)$ para PMV (Tabela 1 ). Para estas variáveis ambas as fontes de $\mathrm{N}$ podem ser utilizadas, pois a produtividade e o teor de MS foram iguais estatisticamente.

Tabela 1. Produção de massa verde (PMV), produção de matéria seca (PMS) e teor de matéria seca (MS) de milheto submetido a quatro doses e duas fontes de nitrogênio no Município de Ceres-GO.

\begin{tabular}{llll}
\hline Fonte de $\mathrm{N}$ & $\mathrm{PMV}\left(\mathrm{kg} \mathrm{ha}^{-1}\right)$ & $\mathrm{PMS}\left(\mathrm{kg} \mathrm{ha}^{-1}\right)$ & $\mathrm{MS}(\%)$ \\
\hline Uréia & $12,210 \mathrm{a}$ & $1,657 \mathrm{a}$ & $13,62 \mathrm{a}$ \\
Novatec & $12,010 \mathrm{a}$ & $1,619 \mathrm{a}$ & $13,59 \mathrm{a}$ \\
\hline Corte & PMV $\left(\mathrm{kg} \mathrm{ha}^{-1}\right)$ & $\mathrm{PMS}\left(\mathrm{kg} \mathrm{ha}^{-1}\right)$ & $\mathrm{MS}(\%)$ \\
\hline 1 & $11,190 \mathrm{a}$ & $1,362 \mathrm{~b}$ & $12,30 \mathrm{~b}$ \\
2 & $13,060 \mathrm{a}$ & $1,691 \mathrm{a}$ & $13,08 \mathrm{~b}$ \\
3 & $12,090 \mathrm{a}$ & $1,862 \mathrm{a}$ & $15,44 \mathrm{a}$ \\
\hline CV (\%) & 27,86 & 27,29 & 9,66 \\
\hline
\end{tabular}

Médias seguidas de mesma letra na coluna são estatisticamente iguais pelo teste de Scott Knott a $5 \%$ de probabilidade.

A PMV para a uréia foi de $12.210 \mathrm{~kg} \mathrm{ha}^{-1}$ semelhante ao Novatec cujo valor foi de $12.010 \mathrm{~kg}$ $\mathrm{ha}^{-1}$, assim como para PMS que a uréia que obteve produção de $1.657 \mathrm{~kg} \mathrm{ha}^{-1}$ e na fonte Novatec de $1.619 \mathrm{~kg} \mathrm{ha}^{-1}$ e para teor de MS foi de 13,62\% e 13,59\% para uréia e Novatec, respectivamente, conforme observado na Tabela 1.

Guimarães Júnior et al. (2009) obtiveram PMV de $12.350 \mathrm{~kg} \mathrm{ha}^{-1}$ de milheto cortado com 37 dias após a emergência com adubação de $73 \mathrm{~kg} \mathrm{ha}^{-1}$ de $\mathrm{N}$, resultados semelhantes aos obtidos nesta pesquisa. Em semeadura no início do mês de março Silva et al. (2003) encontraram PMV de $15.612 \mathrm{~kg} \mathrm{ha}^{-1}$. Ocorreu efeito linear da PMV em função da dose de N, conforme figura 2, ou seja, a PMV aumenta com o acréscimo de $\mathrm{N}$ na adubação independentemente do tipo de fonte nitrogenada que se utiliza.

Estudo realizado por Buso et al. (2015) observaram, para a cultivar ADR-500, que a resposta foi crescente com a elevação da adubação nitrogenada e, atingiu o máximo com a dose de $200 \mathrm{~kg} \mathrm{ha}^{-1}$ de $\mathrm{N}$, com $33.780 \mathrm{~kg} \mathrm{ha}^{-1}$ de PMV. 
Figura 2. Produção de massa verde de forragem de milheto utilizando várias doses e fontes de N.

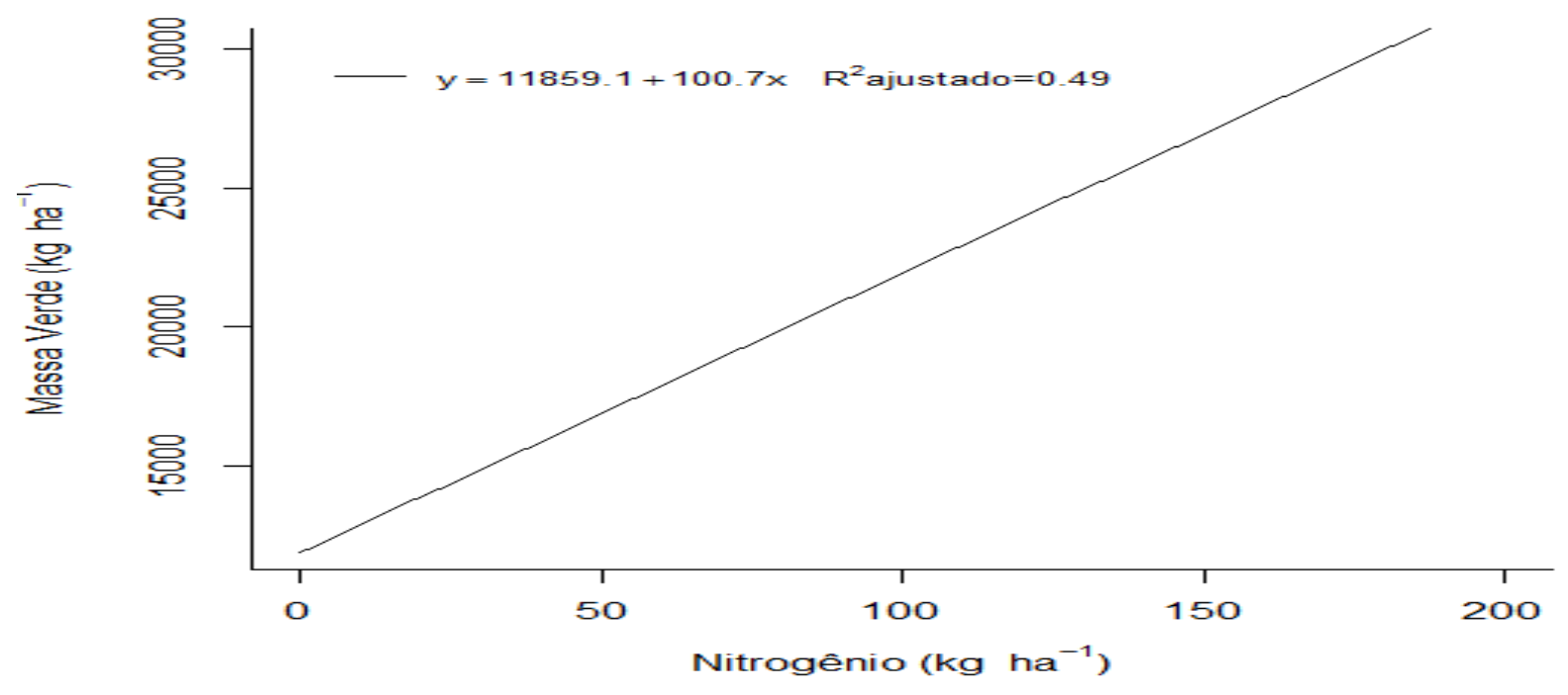

Ocorreu diferença significativa $(P<0,05)$ para $P M S$ entre os cortes conforme Tabela 1 . No primeiro corte devido a uma breve estiagem logo após a emergência proporcionou uma menor PMS (Figura 1), em relação ao segundo e terceiro corte, pois no corte 1 a forrageira apresentou menor número de perfilhos e devido ao corte ter sido realizado no período de maior incidência de chuva (09/03/2013) ocasionou um menor teor de MS, promovendo um efeito na PMS (Tabela 1).

$O$ segundo e terceiro cortes apresentaram maior $P M S, \quad(P<0,05)$ em comparação ao primeiro corte, possivelmente devido ao maior surgimento de folhas e hastes promoveu um incremento na PMS. No trabalho de Silva et al. (2014) trabalharam com três cortes e verificaram efeito contrário maior PMS no primeiro corte e menor no terceiro com PMS de 1.176 e $92 \mathrm{~kg} \mathrm{ha}^{-1}$, respectivamente, produção bem abaixo ao encontrados na presente pesquisa. Conforme a Figura 3 a PMS foi influenciada de forma linear, a medida que aumentou a adubação nitrogenada, ocorrendo aumento na PMS, à medida que, aumentou a adubação com N.

Figura 3. Efeitos de doses de $\mathrm{N}$ na produção de massa seca de forragem de milheto.

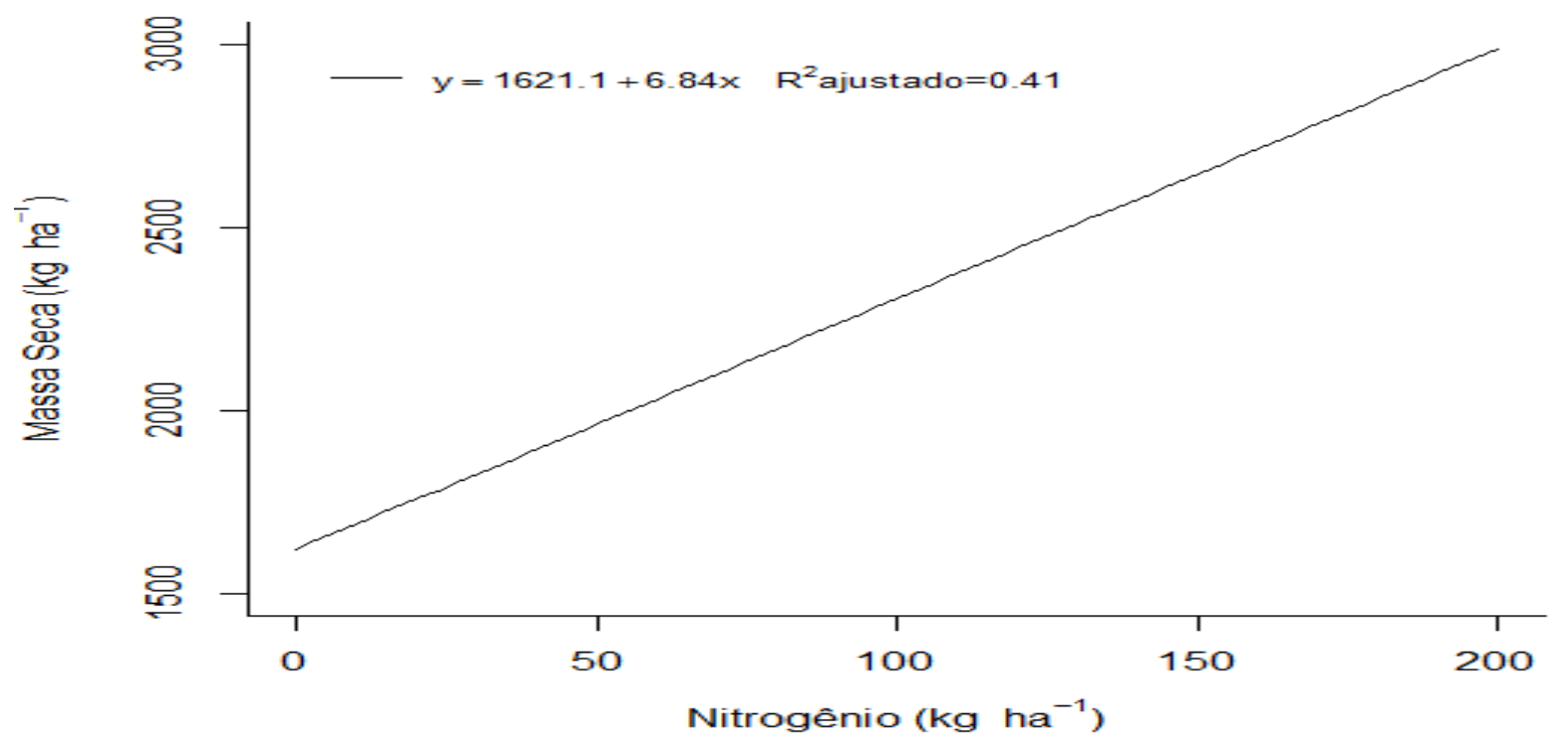


Silva et al. (2012) e Silva et al. (2014) também observaram aumento linear da PMS com o aumento da adubação nitrogenada, quando trabalharam com as doses de 0, 50, 100 e 150 e 0, 40, 80 e $160 \mathrm{~kg} \mathrm{ha}^{-1}$ de N, respectivamente. Negreiros Neto et al. (2010) relatam resposta linear de produção de milheto avaliado sob doses de $\mathrm{N}$, quando obtiveram a produção máxima de $\mathrm{MS}$ com a aplicação de $120 \mathrm{~kg}$.ha ${ }^{1}$ de N. No trabalho de Buso et al. (2015) observaram efeito quadrático e a dose de maior PMS foi de 157,5 kg.ha ${ }^{1}$ de N. Segundo os mesmos autores doses elevadas de N podem promover perdas por lixiviação e reduzir a disponibilidade deste nutriente para a planta.

Para o teor de MS existiu diferença significativa $(P<0,05)$ entre os cortes (Tabela 1$)$. 0 terceiro corte apresentou teor de MS de $15,44 \%$, pois a redução de disponibilidade de água no solo proporcionou maior acúmulo de MS na parte aérea das plantas de milheto. Costa et al. (2011) encontraram teores médios de MS de 15,2\%, determinado no milheto cortado aos 35 dias após a semeadura, com a aplicação de $67 \mathrm{~kg} \mathrm{ha}^{-1}$ de $\mathrm{N}$. Resultados que correspondem ao terceiro corte da presente pesquisa.

Resultados obtidos por Buso et al. (2014) que trabalhou com duas épocas de semeadura e encontrou valores médios de 9,95 e 10,59\%, para dezembro/2010 e fevereiro/2011, respectivamente. De acordo com os autores a maior concentração de MS na semeadura da safrinha, provavelmente, pode ser explicado em função das condições climáticas, onde se verificou menor ocorrência de chuvas e, consequentemente, maior radiação solar. Esta situação proporcionou menor quantidade de água acumulada na parte aérea da planta, o que contribuiu para aumento no teor de MS.

$\mathrm{O}$ teor de MS foi influenciado de forma linear ao aumento da dose de $\mathrm{N}$, conforme Figura 4. Este efeito demonstra que a MS cresceu à medida que acrescentou $\mathrm{N}$ em cobertura. No trabalho de Buso et al. (2014) que trabalharam com doses de 0 a $200 \mathrm{~kg} \mathrm{ha}^{-1}$ de $\mathrm{N}$, aplicados em cobertura, observaram influência quadrática onde a dose $126 \mathrm{~kg} \mathrm{ha}^{-1}$ alcançou o máximo teor de MS.

Figura 4. Efeito de doses de $\mathrm{N}$ nos teores de matéria seca (MS) de forragem de milheto forrageiro.

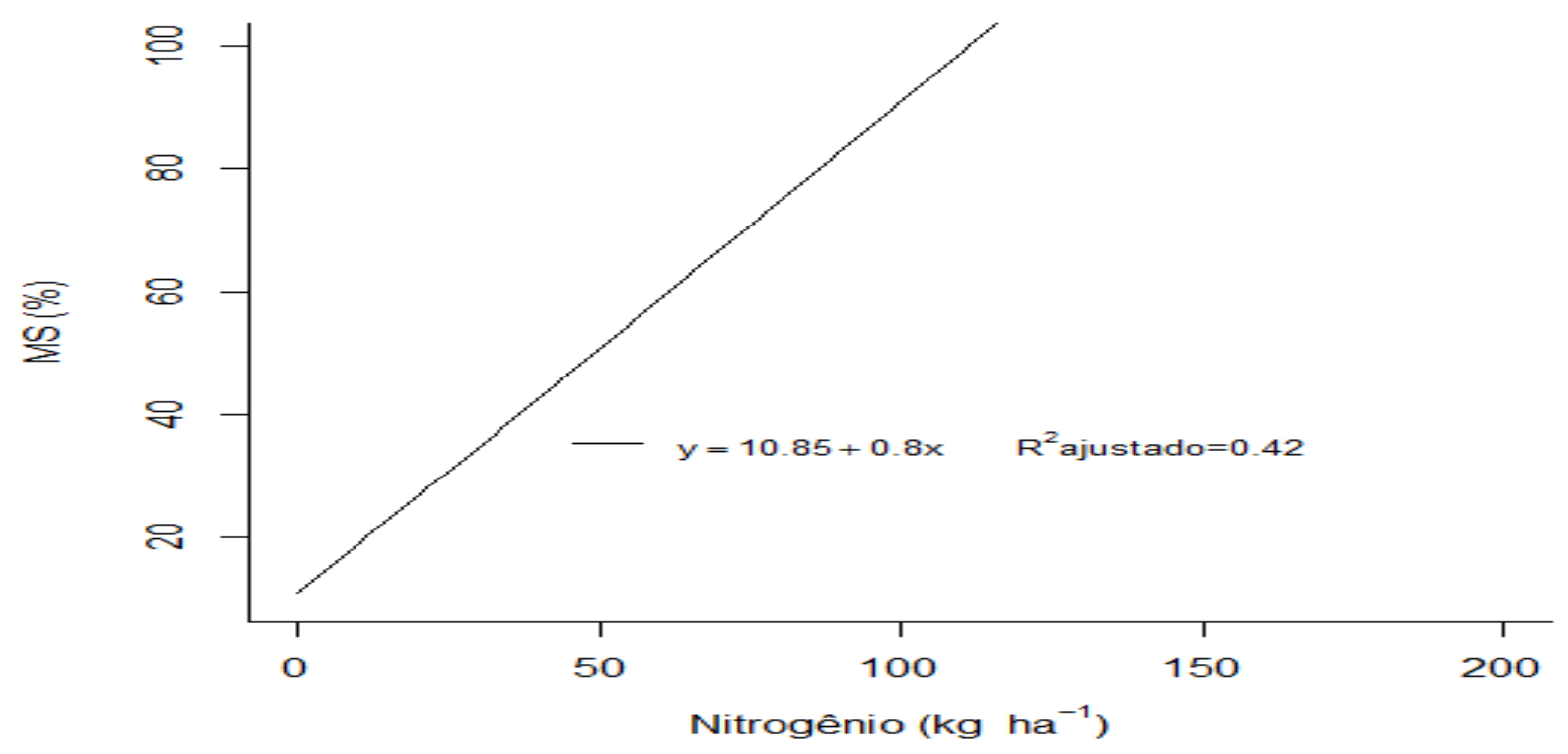

Não ocorreu diferença significativa $(p>0,05)$, para $N$ contido na planta (NC) e PB $\left(k^{2} h^{-1}\right)$, para as fontes de $\mathrm{N}$ e os cortes realizados, conforme apresentados na Tabela 2. Ocorreu efeito linear para NC $(y=72,33+0,39 x)$ e para PB $(y=452,06+2,45 x)$ indicando que a disponibilidade de 
$\mathrm{N}$ promoveu maior absorção à medida que ocorreu o desenvolvimento da cultura e a realização dos cortes, devido às plantas já possuírem sistema radicular bem desenvolvido.

No trabalho de Silva et al. (2014) relataram influência linear com o aumento das doses de N de 0 para $160 \mathrm{~kg} \mathrm{ha}^{-1}$. Os mesmos autores relatam ainda que quando nenhum fator edafoclimático é limitante nem ocorrem grandes perdas de nitrogênio por volatilização e há nitrogênio disponível na solução do solo, os cultivares de milheto conseguem absorver quantidades satisfatórias desse nutriente.

Tabela 2. Produção de proteína bruta (PB), nitrogênio contido (NC), proteína bruta na MS (PB \%), Fibra em Detergente Neutro (FDN) Fibra em Detergente ácido (FDA) de milheto submetido a quatro doses e duas fontes de nitrogênio no município de Ceres-GO.

\begin{tabular}{llllll} 
Fonte N & PB $\left(\mathrm{kg} \mathrm{ha}^{-1}\right)$ & $\mathrm{NC}\left(\mathrm{kg} \mathrm{ha}^{-1}\right)$ & PB (\%) & FDN (\%) & FDA (\%) \\
\hline Ureia & $456,25 \mathrm{a}$ & $73,00 \mathrm{a}$ & $17,60 \mathrm{a}$ & $47,68 \mathrm{a}$ & $29,33 \mathrm{a}$ \\
Novatec & $460,09 \mathrm{a}$ & $73,61 \mathrm{a}$ & $18,47 \mathrm{a}$ & $47,04 \mathrm{a}$ & $29,20 \mathrm{a}$ \\
\hline \multirow{2}{*}{ Corte } & PB (kg ha $\left.{ }^{-1}\right)$ & $\mathrm{NC}\left(\mathrm{kg} \mathrm{ha}^{-1}\right)$ & PB (\%) & FDN (\%) & FDA (\%) \\
\hline 1 & $422,02 \mathrm{a}$ & $67,52 \mathrm{a}$ & $20,15 \mathrm{a}$ & $46,23 \mathrm{~b}$ & $28,44 \mathrm{~b}$ \\
2 & $469,74 \mathrm{a}$ & $75,16 \mathrm{a}$ & $17,84 \mathrm{~b}$ & $47,34 \mathrm{~b}$ & $28,80 \mathrm{~b}$ \\
3 & $482,75 \mathrm{a}$ & $77,24 \mathrm{a}$ & $16,10 \mathrm{c}$ & $48,50 \mathrm{a}$ & $30,55 \mathrm{a}$ \\
\hline CV (\%) & 16,96 & 15,43 & 10,58 & 5,82 & 5,36
\end{tabular}

Médias seguidas de mesma letra na coluna são estatisticamente iguais pelo teste de Scott knott a $5 \%$ de probabilidade.

O teor de PB diferiu significativamente $(\mathrm{P}<0,05)$ em todos os cortes onde o primeiro corte apresentou teor de $20,15 \%$ diferindo do segundo corte com teor de $17,84 \%$ e o terceiro corte diferiu dos demais com teor de 16,10\% (Tabela 2). Esta redução no teor de PB com o avanço dos cortes se deve ao fato da redução na disponibilidade de $\mathrm{N}$ proveniente da adubação ao longo do desenvolvimento das plantas e da redução na disponibilidade de água, que também pode influenciar na absorção de $\mathrm{N}$.

De acordo com Buso et al. (2014) verificaram diferença significativa para PB entre as épocas de semeadura, cujos valores médios foram de 22,46 e 20,86\%, para dezembro e fevereiro, respectivamente. Com semeadura em fevereiro, Queiroz et al. (2012) obtiveram 16,14\% de PB com colheita aos 30 dias. Camargo et al. (2009) relatam teores de médios de $20 \%$ PB em pastagem de milheto com adubação de $100 \mathrm{~kg} \mathrm{ha}^{-1}$ de $\mathrm{N}$ aos 21 dias após a germinação.

Estes resultados corroboram com os valores obtidos nesta pesquisa, já que também foram observados altos teores de PB, provavelmente, devido grande presença de folhas disponíveis no momento dos cortes da planta forrageira no primeiro corte e após este período os teores decresceram. No trabalho de Costa et al. (2011), encontraram teor de PB na faixa de foi $16,4 \%$, em área de pastejo com milheto, utilizada aos 35 dias após a semeadura e com aplicação de $67 \mathrm{~kg} \mathrm{ha}^{-}$ 1 , teor correspondente ao terceiro corte $(16,10 \%)$ encontrados na presente pesquisa.

Leão et al. (2012) trabalharam com quatro cortes quando as plantas de milheto atingiram $0,80 \mathrm{~m}$ e verificaram queda no teor de PB com o avanço dos cortes cujos teores foram de 15,26; 14,$89 ; 13,64$ e $9,58 \%$ do primeiro ao quarto corte, respectivamente, a redução dos teores de $\mathrm{PB}$ com o avanço dos cortes ocorreram devido a morte dos perfilhos com o avanço do ciclo. 
O teor de PB apresentou comportamento linear para as doses de $\mathrm{N}$ utilizadas, conforme Figura 5. Na pesquisa desenvolvida por Buso et al. (2014) ocorreu aumento do teor de PB até a dose de $125,5 \mathrm{~kg} \mathrm{ha}^{-1}$ de $\mathrm{N}$, conforme derivação da equação de regressão quadrática. Após esta dosagem os teores de PB reduziram. Pinho et al. (2014) verificaram efeito quadrático e o maior teor de PB foi com dose de $79,80 \mathrm{~kg} \mathrm{ha}^{-1}$ de $\mathrm{N}$.

Figura 5. Efeito das doses de $\mathrm{N}$ nos teores de Proteína Bruta (PB) de milheto forrageiro.

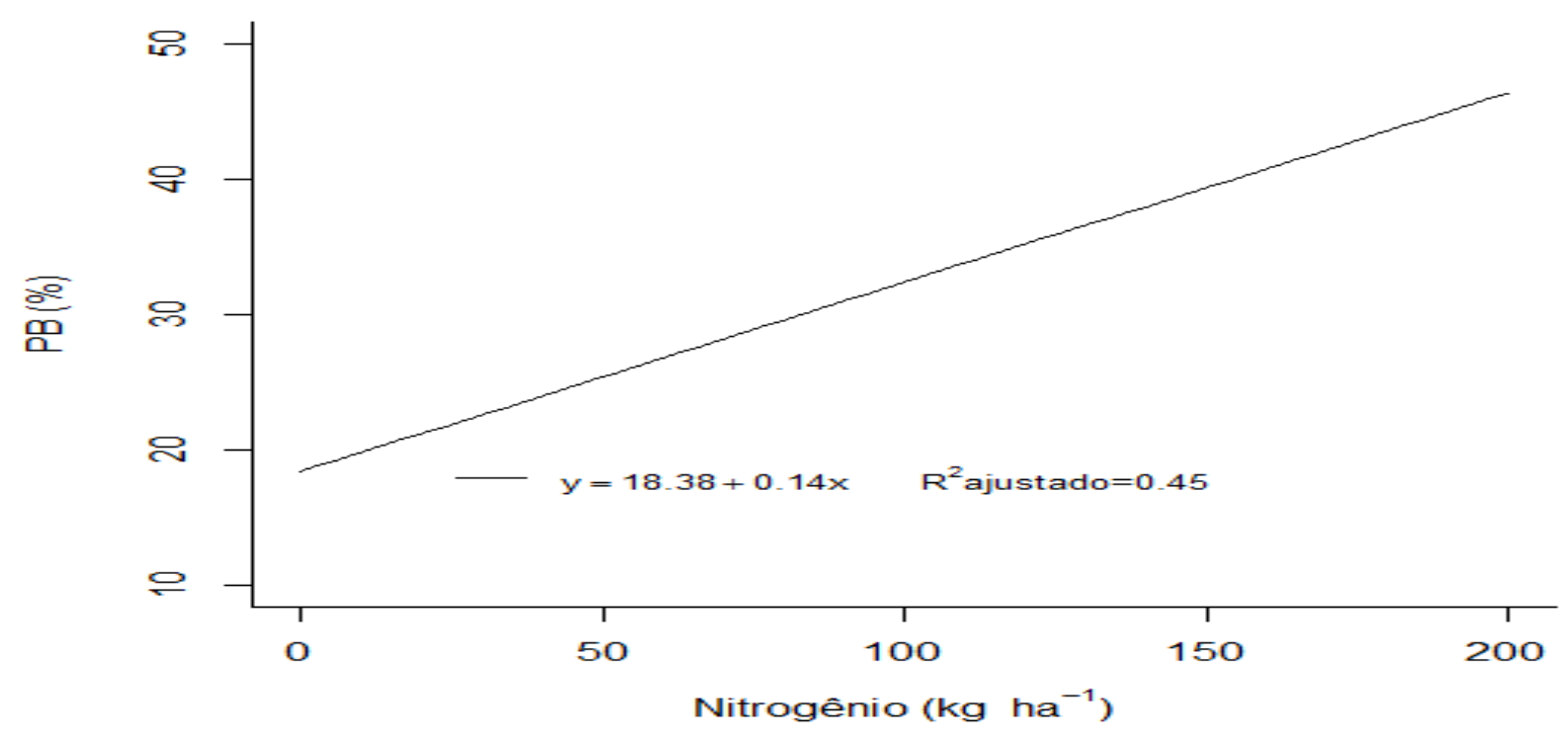

Para a FDN não foi observado diferença significativa $(P>0,05)$ para as fontes de $N$, cujos teores são apresentados na Tabela 2. Desta forma a duas fontes podem ser utilizadas para fornecimento de $\mathrm{N}$ para a cultura do milheto, pois disponibilizaram $\mathrm{N}$ ao longo do ciclo de pastejo do milheto.

Ocorreu diferença estatística $(P<0,05)$ entre os cortes (Tabela 2$)$. No terceiro corte o teor foi de $48,50 \%$ e diferiu do primeiro e segundo que foram estatisticamente iguais, cujos teores foram 47,34 e $46,23 \%$, respectivamente. A maior presença da FDN no terceiro corte se justifica pela queda de PB na MS com o avanço dos cortes (Tabela 2), devido ao possível aumento na presença de caules em relação a folhas. Como relatado no trabalho de Kollet et al. (2006) com três idades de cortes $(35,42$ e 49 dias) observaram que à medida em que aumentava a idade de corte do milheto ocorreu aumento dos teores de FDN, de $54,30 \%$ para $69,17 \%$, aos 35 e 49 dias, respectivamente, e FDA, de $31,43 \%$ para $36,97 \%$, para o mesmo período.

Estas variações são atribuídas a redução de lâminas foliares e aumento das hastes, elevando os componentes fibrosos. Queiroz et al. (2012) trabalharam com a cultivar BRS 1501 e encontraram teores de FDN de 52,97; 48,86 e 55,29\% para contes em fevereiro, março e abril, respectivamente.

Em trabalho conduzido em pastagem de milheto Jochims et al. (2010) encontraram valores médios de FDN, de 59,29\%, com aplicação de $135 \mathrm{~kg} \mathrm{ha}^{-1}$ de $\mathrm{N}$, parcelado em três vezes. No trabalho de Scaravelli et al. (2007) são relatados valores médios de 57,39\% de FDN também em pastagem de milheto, aos 53 dias de crescimento vegetativo, com a aplicação de $80 \mathrm{~kg} \mathrm{ha}^{-1} \mathrm{de} \mathrm{N}$. Costa et al. (2011) observaram teor de $61,9 \%$, em pasto de milheto aos 35 dias após a semeadura.

Em trabalho conduzido por Camargo et al. (2009) são relatados teores médios de FDN de $50 \%$, para pastagem de milheto com pastejo realizado aos 21 dias após a emergência, com aplicação de $100 \mathrm{~kg} \mathrm{ha}^{-1}$ de N. Silva et al. (2012) trabalharam com três cortes (8/03, 21/03 e 
11/04/2006) e também observaram aumento da FDN, conforme aumentou a idade dos cortes, resultados semelhantes aos encontrados na presente pesquisa.

A FDN apresentou comportamento linear $(y=48,44+0,43 x)$, teores crescentes à medida que aumentou a dose de N. No trabalho de Vitor et al. (2009) que obtiveram efeito linear decrescente dos teores de FDN, quando avaliaram o capim-elefante durante o ano todo, em função do aumento da dose de N, com valores de 73,87 e 71,59\% de FDN para as doses de 100 e $700 \mathrm{~kg} \mathrm{ha}^{-1}$ de N, respectivamente. Pinho et al. (2014) verificaram efeito linear crescente da FDN em função de doses de $N\left(0,20,40,60\right.$ e $\left.80 \mathrm{~kg} \mathrm{ha}^{-1}\right)$. Buso et al. (2014) encontraram efeito quadrático e ocorreu aumento da FDN a partir da dose de $118 \mathrm{~kg} \mathrm{ha}^{-1} \mathrm{de} \mathrm{N}$.

A FDA não apresentou diferença estatística $(P>0,05)$ entre as fontes de $N$, conforme Tabela 2 , cujos teores foram de 29,33 e 29,22\% para ureia e Novatec, respectivamente. Ocorreu diferença estatística $(P<0,05)$ entre os cortes (Tabela 2$)$. 0 terceiro corte diferiu dos demais cujo teor foi de $30,55 \%$.

Os valores de FDA obtidos nesta pesquisa são semelhantes aos preconizado por Mertens (1994), quando estabelece o valor máximo de 30\%, como sendo o ideal para que ocorra maior consumo de forragem e melhor digestibilidade da forrageira consumida. Silva et al. (2012) também verificaram aumento nos teores de FDA com o avanço dos cortes da parte aérea cujos teores 25,90 a $40,87 \%$ do primeiro para o terceiro corte.

Os resultados obtidos pelos autores indicam que, com a realização dos cortes há aumento nos teores de FDA pelo aumento da fração colmo em relação a folhas, o mesmo foi observado por Leão et al. (2012) que trabalharam com quatro cortes e verificaram aumento no teor de FDA com o avanço dos cortes realizados quando as plantas atingiram a $0,80 \mathrm{~m}$ cujos teores foram 38,00 ; 38,$14 ; 38,65$ e $43,25 \%$ do primeiro ao quarto corte, respectivamente.

A FDA apresentou efeito linear $(y=27,22+0,38 x)$, ou seja, ocorreu incrementos nos teores com o aumento da adubação nitrogenada. No trabalho de Buso et al. (2014) observaram resposta quadrática, onde o menor teor de FDA foi verificado na dose de $139 \mathrm{~kg} \mathrm{ha}^{-1}$ de N.

\section{CONCLUSÕES}

Diante dos resultados inerentes a avaliação de diferentes doses e fontes de $\mathrm{N}$ na produção, composição bromatológica e $\mathrm{N}$ contido na parte aérea das plantas de milheto forrageiro em condições de cerrado, verificou-se que as duas fontes de $\mathrm{N}$ são adequadas para o fornecimento deste nutriente para a cultura do milheto e quanto maior a dose maior a produção de massa verde e massa seca.

\section{REFERÊNCIAS}

BUSO, W.H.D.; FRANÇA, A.F.S.; MIYAGI, E.; CORRÊA, D.S. Nitrogen in the production of green and dry mass and the Efficiency of nitrogen conversion and apparent recovery of pearl millet cultivars. Biosciense Journal, Uberlândia, v.31, n.6, p.1778-1786. 2015. http://dx.doi.org/10.14393/BJ$\underline{\text { v31n6a2015-26164 }}$

BUSO, W.H.D.; FRANÇA, A.F.S.; MIYAGI, E. S. Bromatological composition and dry matter digestibility of millet cultivars subjected to nitrogen doses. Arquivos Brasileiros de Medicina Veterinária e Zootecnia, Belo Horizonte, v.66, n.3, p.887-893. 2014. http://dx.doi.org/10.1590/1678-41626746

CAMARGO, D.G.; ROCHA, M.G.; KOZLOSKI, G.V.; ELEJALDE, D.G.; BREMM, C.; POTTER, L.; ROSA, A.T.N.; NETO, R.A.O. Consumo de forragem por cordeiras suplementadas em pastagem de milheto. 
Ciência Rural, Santa Maria, v.39, n.2, p.509-514. 2009. http://dx.doi.org/10.1590/S0103$\underline{84782008005000083}$

COSTA, V.G.; ROCHA, M.G.; POTTER, L. ROSO, D.; ROSA, A.T.N.; REIS, J. Comportamento de pastejo e ingestão de forragem por novilhas de corte em pastagens de milheto e papua. Revista Brasileira de Zootecnia, Viçosa, v.40, n.2, p.251-259. 2011. http://dx.doi.org/10.1590/S1516$\underline{35982011000200004}$

FAGUNDES, J. L.; FONSECA, D. M.; MORAIS, R. V. M.; MISTURA, C.; VITOR, C. M. T.; GOMIDE, J. A.; NASCIMENTO JUNIOR, D.; SANTOS, M. E. R.; LAMBERTUCCI, D. M. Avaliação das características estruturais do capim-Braquiária em pastagens adubadas com nitrogênio nas quatro estações do ano. Revista Brasileira de Zootecnia, Viçosa, v.35, n.1, p.30-37. 2006. http://dx.doi.org/10.1590/S1516-35982006000100004

FRIBOURG, H. A. Summer annual grasses. In: HEAT, M. E.; BARNES, R.F.; METCALFE, D. S. Forages: the science of grassland agriculture. Iowa State University. Ames, lowa. 4. ed. p.278-286. 1985.

GUIMARÃES JÚNIOR, R.; GONÇALVES, L.C.; RODRIGUES, J.A.S.; PIRES, D.A.A.; JAYME, D.G.; RODRIGUEZ, N.M.; SALIBA, E.O.S. Avaliação agronômica de genótipos de milheto ( $P$. glaucum) plantados em período de safrinha. Archivos de Zootecnia, Córdoba, v.58, suplemento.1, p.629632. 2009.

JOCHIMS, F.; PIRES, C.C.; GRIEBLER, L.; BOLZAN, A.M.S.; DIAS F.D.; GALVANI, D.B. Comportamento ingestivo e consumo de forragem por cordeiras em pastagem de milheto recebendo ou não suplemento. Revista Brasileira de Zootecnia, Viçosa, v.39, n.3, p.572-581, 2010. http://dx.doi.org/10.1590/S1516-35982010000300017

KOLLET, J.L.; DIOGO, J.M.S.; LEITE, G.G. Rendimento forrageiro e composição bromatológica de variedades de milheto (Pennisetum glaucum(L.) R. BR.). Revista Brasileira de Zootecnia, Viçosa, v.35, n.4, p.1308-1315. 2006. http://dx.doi.org/10.1590/S1516-35982006000500008

LEÃO, H.F.; COSTA, K.A.P.; DIAS, F.J.S.; SEVERIANO, E.C.; COLLAO-SAENZ, E.A.; SIMON, G.A. Production and bromatological composition of pearl Millet genotypes for pasture manned in different cutting heights. Bioscience Journal, Uberlândia, v.28, n.6, p.903-912. 2012.

MERTENS D.R. Regulation of forage intake. In: Forage quality, evaluation and utilization. Madison: American Society of Agronomy, 450-493. 1994.

NEGREIROS NETO, J.V.; SANTOS, A.C.; LEITE, R.L.L.; CRUZ, R.S. Análise de diferentes doses de nitrogênio e espaçamentos em milheto no norte do Tocantins. Revista Biotemas, v.23, n.4, p.1923. 2010. http://dx.doi.org/10.5007/2175-7925.2010v23n4p19

PINHO, R.M.A.; SANTOS, E.M.; CAMPOS, F.S.; RAMOS, J.P.F.; MACEDO, C.H. OL; BEZERRA, H.F.C.; PERAZZO, A.F. Silages of pearl millet submitted to nitrogen fertilization. Ciência Rural, Santa Maria, v.44, n.5, p.018-924. 2014. http://dx.doi.org/10.1590/S0103-84782014000500025

QUEIROZ, D.S.; SANTANA, S.S.; MURÇA, T.B.; SILVA, E.A.; VIANA, M.C.M.; RUAS, J.R.M. Cultivares e épocas de semeadura de milheto para produção de forragem. Revista Brasileira de Saúde e Produção Animal, Salvador, v.13, n.2, p.318-329. 2012. https://doi.org/10.1590/S1519- 
R Development Core Team. R: A language and environment for statistical computing. R Foundation for Statistical Computing, Vienna, Austria. ISBN 3-900051-07-0, URL http://www.R-project.org. 2014.

SANTOS, D.T.; ROCHA, M.G.; QUADROS, F.L.F.; GENRO, T.C.M.; MONTAGNER, D.B.; GONÇALVES, E.N.; ROMAN, J. Suplementos energéticos para recria de novilhas de corte em pastagens anuais: desempenho animal. Revista Brasileira de Zootecnia, Viçosa, v.34, n.1, p.209-219. 2005. http://dx.doi.org/10.1590/S1516-35982005000100025

SCARAVELLI, L.F.B.; PEREIRA, L.E.T.P.; OLIVO, C.J.; AGNOLIN, C.A. Produção e qualidade de pastagens de Coastcross-1 e milheto utilizadas com vacas leiteiras. Ciência Rural, Santa Maria, v. 37, n.3, p.841-846. 2007. http://dx.doi.org/10.1590/S0103-84782007000300037

SILVA, A.G.; FRANÇA, A.F.S.; MIYAGI, E.S.; DAMBROS, C.E.; LOPES, F.B. Eficiência da fertilização fosfatada e nitrogenada em cultivares de milheto. Ciência Animal Brasileira, Goiânia, v.15, n.2, p.119-127. 2014. http://dx.doi:10.1590/1809-6891v15i29010

SILVA, A.G.; FARIAS JÚNIOR, O.L.; FRANÇA, A.F.S.; MIYAGI, E.S.; RIOS, L.C.; MORAES FILHO, C.G.; FERREIRA, J.L. Rendimento forrageiro e composição bromatológica de milheto sob adubação nitrogenada. Ciência Animal Brasileira, Goiânia, v.13, n.1, p.67-75. 2012. http://dx.doi:10.5216/cab.v13i1.1434

SILVA, G.F.; ERASMO, E.A.L.; SARMENTO, R.A.; SANTOS, A.S.; AGUIAR, R.W.S. Potencial de produção de biomassa e matéria seca de milheto (Pennisetum americanum Schum.), em diferentes épocas no sul do Tocantins. Bioscience Journal, Uberlândia, v.19, n.3, p.31-34. 2003.

SILVA, D.J.; QUEIROZ, A.C. Análise de alimentos (Métodos químicos e biológicos). Viçosa, MG: Universidade Federal de Viçosa, 2002. 340p.

SIMILI, F.F.; GOMIDE, C.A.M.; MOREIRA, A.L.; REIS, R.A.; LIMA, M.L.P.; PAZ, C.C.P. Resposta do híbrido de sorgo-sudão à adubação nitrogenada e potássica: características estruturais e produtivas. Ciência e Agrotecnológia, Lavras, v.34, n.1, p.87-94. 2010. http://dx.doi.org/10.1590/S1413-70542008000200020

SPEHAR, C.R.; TRECENTI, R. Desempenho agronômico de espécies tradicionais e inovadoras da agricultura em semeadura de sucessão e entressafra no cerrado do planalto central brasileiro. Bioscience Journal, Uberlândia, v.27, n.1, p.102-111. 2011.

VITOR, C.M.T.; FONSECA, D.M.; CÓSER, A.C.; MARTINS, C.E.; NASCIMENTO JÚNIOR, D.; RIBEIRO JÚNIOR, J.I. Produção de matéria seca e valor nutritivo de pastagem de capim-elefante sob irrigação e adubação nitrogenada. Revista Brasileira de Zootecnia, Viçosa, v.38, n.3, p.435-442. 2009. http://dx.doi.org/10.1590/S1516-35982009000300006 